\title{
Erratum to: Analytical Investigation of Carrier Concentration Effect on One-Dimensional Graphene Nanoscroll
}

\author{
Authors: M. J. Kiani,* E. Akbari, F. Rahmanian Kooshkaki, and A. Zeinalinezhad \\ Erratum to: Electron. Mater. Lett., Vol. 12, No. 2 (2016), pp. 219-223 \\ DOI: 10.1007/s13391-015-5352-y
}

Correction 1

M. J. Kiani is the corresponding author and his affiliation is Department of Electrical Engineering, Islamic Azad University, Yasooj Branch, Yasooj, Iran

Correction 2

\section{ACKNOWLEDGEMENTS}

Authors would like to acknowledge the financial support from Research University facilities of the Azad university of yasooj. Also thanks to the Research Management Center of Azad university of yasooj for providing excellent research environment in which this work was complete.

*Corresponding author: kianiph@gmail.com

The online version of the original article can be found at http://dx.doi.org/10.1007/s13391-015-5352-y.

CKIM and Springer 